\title{
A NOÇÃo HUSSERLIANA DE MUNDO DA VIDA (LEBENSWELT): EM DEFESA DE SUA UNIDADE E COERÊNCIA ${ }^{1}$
}

\author{
Juliana Missaggia ${ }^{2}$
}

\begin{abstract}
Resumo: Neste artigo, investigo algumas questôes controversas acerca do conceito de mundo da vida (Lebenswelt), no pensamento de Edmund Husserl, defendendo que tal noção deve ser lida de maneira unívoca, apesar dos seus diferentes usos, e que pode ser compreendida como um conceito que mantém coerência interna com relação à obra do filósofo. Para uma apresentação completa desse último aspecto, analiso a ligação entre mundo da vida e ciência, bem como a questâo de seu papel no conhecimento e o vínculo com a noção de intersubjetividade - todos esses temas centrais do pensamento husserliano tardio.
\end{abstract}

Palavras-chave: Edmund Husserl. Mundo da vida. Ciência. Conhecimento. Intersubjetividade.

\section{A IMPORTÂNCIA DO CONCEITO DE LEBENSWELT E AS DIFICULDADES EM TORNO DA SUA EQUIVOCIDADE}

Dentre todas as noçóes de mundo elaboradas por Husserl, o conceito de "mundo da vida" ou "mundo vivido" (Lebenswelt) é sem dúvida um dos mais discutidos, assim como o mais influente dentro da tradição fenomenológica como um todo, tendo sido utilizado, em diferentes sentidos e contextos, por diversos filósofos depois de Husserl. ${ }^{3}$ Desenvolvida na chamada "fase tardia" do pensamento husserliano, a concepção de mundo da vida traz dificuldades pela equivocidade presente em seus usos, o que acabou por motivar diferentes interpretaçóes. A noção de mundo da vida é tida por muitos como um elemento discrepante em relação às demais concepçóes de mundo que aparecem na obra de Husserl, sendo questionável em que

\footnotetext{
${ }^{1}$ http://dx.doi.org/10.1590/S0101-31732018000100009

${ }^{2}$ Professora do Departamento de Filosofia e do Programa de Pós-Graduação em Filosofia na Universidade Federal de Santa Maria (UFSM), Santa Maria, RS - Brasil. E-mail: juliana.missaggia@ufsm.br

Desenvolve pesquisa nas áreas de Fenomenologia, Existencialismo e Ética.

${ }^{3} \mathrm{Na}$ verdade, conforme lembra Zahavi (2003, p.125), parte da importância que tem a noção de mundo da vida ainda hoje se deve ao fato de que ela transcendeu a esfera da filosofia e foi apropriada também por parte da sociologia, como é o caso de Schütz e Luckmann (2006). Habermas (1981) se utilizou igualmente do termo, ainda que em um contexto teórico distinto.
} 
medida poderia estar de acordo com um conceito mais amplo de mundo. ${ }^{4}$ No âmbito de uma investigação mais abrangente, sua análise é importante para a compreensão do idealismo husserliano, pois confirmaria, entre outras questôes, que a fenomenologia abriga um conceito de mundo que transcende em muito o método solipsista, sendo essa uma das objeções mais frequentes ao método fenomenológico.

Em uma definição geral, podemos entender mundo da vida como a experiência e o conjunto coerente de vivências pré-científicas, como "[...] o mundo permanentemente dado como efetivo na nossa vida concreta" (HUSSERL, Krisis, $\$ 9$, p. 51 , p. 40$)^{5}$, em contraste com o mundo propriamente científico, no qual a realidade é analisada a partir dos elementos próprios da ciência corrente, com seus correspondentes pressupostos e orientaçôes de método, sejam tais pressuposiçôes explícitas ou não. Como se pode notar, o procedimento inicial de definição se faz, como que opositivamente, com base em um confronto com a concepção "científica" de mundo e realidade. Nesse sentido, a noção de mundo da vida está diretamente relacionada com a crítica empreendida por Husserl não apenas ao método científico e sua epistemologia oculta, mas também à atividade concreta do fazer científico e suas diversas implicaçóes, tanto filosóficas como existenciais e éticas.

Apesar de ser desenvolvido sobretudo na obra Die Krisis der europäischen Wissenschaften und die transzendentale Phänomenologie, o termo "mundo da vida” já aparece em diversos trabalhos anteriores de Husserl, incluindo Cartesianische Meditationen e Phänomenologische Psychologie. (HUSSERL, 1950, p. 160 ss., 1962, p.55-56). O que ocorre, porém, é que o filósofo não oferece, antes de Krisis, uma definição precisa para o conceito, de modo que poderia ser questionado em que medida ele já estava suficientemente elaborado, no pe-

\footnotetext{
${ }^{4}$ Carr (1974, p. 170 ss.) sustenta que, com a noção de mundo da vida, Husserl realiza uma alteração tanto do conceito de mundo, em seu pensamento, quanto faz uma crítica geral a diversos elementos do método que vinha desenvolvendo. Para uma análise abrangente da relação entre mundo da vida e o conceito de mundo, ver também Dodd (2005, p. 149-174). Conforme explicitarei a seguir, não concordo que esse conceito traga uma mudança táo radical: primeiro, porque Husserl mantém, ainda que com algumas reelaboraçóes, os métodos de redução no contexto da filosofia do mundo da vida; depois, porque essa noçấo já vinha sendo desenvolvida em trabalhos anteriores e já era uma preocupação para o filósofo, antes de seu desenvolvimento maduro, que ocorreria somente em Die Krisis der europäischen Wissenschaften und die transzendentale Phänomenologie.

5 Para a citação das obras de Husserl, utilizo, geralmente, o nome reduzido do livro ("Krisis", por exemplo), seguido da paginação no original e, quando disponível, da página correspondente na tradução em língua portuguesa, a qual cito. Eventualmente, altero a tradução, casos nos quais acrescento "t.a.", "tradução alterada". Nas obras usadas das quais não há versão em nosso idioma, a tradução citada é de minha responsabilidade.
} 
ríodo. Um indício, entretanto, de que Husserl já vinha desenvolvendo a noção de mundo da vida e a crítica à ciência, antes dos anos 30, é a obra Ideen zu einer reinen Phänomenologie und phänomenologischen Philosophie, Zweites Buch: Phänomenologische Untersuchungen zur Konstitution (doravante Ideen II), na qual encontramos uma reflexão sobre a atitude teórica e científica quanto à natureza e aquilo que ela não inclui, em suas análises:

A ciência natural, embora investigue a totalidade das realidades, não trata [da questáo] do mundo da vida pessoal, e mesmo a mais sutil teoria da ciência natural náo dá conta do mundo da vida, simplesmente porque a direção temática que o pensamento do cientista natural segue em direção à realidade da vida é um caminho teórico, deixando desde o princípio essa questáo de lado e apenas tratando disso a partir da tecnologia e a partir da aplicação da ciência natural à vida. [...] O mundo da vida é o mundo natural - na atitude da vida natural, somos sujeitos vivos atuantes junto a outros sujeitos atuantes em um círculo aberto. (HUSSERL, Ideen II, p. 374-375).

O mundo da vida, portanto, diz respeito ainda à vida partilhada com outros sujeitos, na qual todos atuam como pertencentes a um mundo comum. Como já pode ser entrevisto, e conforme será explicitado a seguir, a noção de mundo da vida está diretamente relacionada à intersubjetividade, sendo essa uma das razóes pelas quais, por vezes, é tida como uma concepção nova e em certo sentido incompatível com o método solipsista que guiou a virada idealista da fenomenologia. Também é importante sua relação com a ciência natural: ainda que esta se proponha abranger todos os aspectos da realidade, ela não dá conta da esfera concreta do mundo da vida, e isso ocorre em função do que Husserl reconhece como uma orientação teórica que condiciona a investigação científica desde suas origens, impedindo-a de tratar das vivências de caráter pré-científico.

Mas a principal dificuldade em torno da questão é a equivocidade do conceito: como apontam diversos intérpretes ${ }^{6}$, Husserl utiliza "mundo da vida” com sentidos distintos, e isso se dá mesmo em Krisis, de modo que não é possível atribuir tal ambiguidade a uma "evolução" na elaboração do termo. Assim, as diferentes interpretaçôes, por vezes, defendem a ideia de que há uma

${ }^{6}$ CARR, David, Husserl's problematic concept of the life-world, p. 202-212; HELD, Klaus. Husserl's phenomenology of the life-world, p. 59-61; RUSSELL, Matheson. Husserl: a guide for the perplexed, p. 194-195; DRUMMOND, John J. Historical dictionary of Husserl's philosophy, p. 122; ZAHAVI, Dan. Husserl's phenomenology, p. 129-130. 
unidade geral, a despeito de tal diversidade de sentidos. É igualmente nessa linha que segue a leitura aqui apresentada, embora, como será indicado a seguir, com ressalvas quanto às interpretaçóes mencionadas.

No que concerne, em primeiro lugar, à ligação de mundo da vida com a noçáo husserliana mais ampla de mundo, entendo que esse novo conceito representa apenas em parte uma novidade em relaçáo ao conceito geral de mundo ${ }^{7}$, mas de modo algum implica uma ruptura: trata-se, em certo sentido, de uma inovação, na medida em que Husserl sistematiza e dá nome para uma esfera que antes, mesmo presente, não ocupava um lugar central no seu pensamento. Além disso, a meu ver, os conceitos são conciliáveis, e isso não na medida em que teriam o mesmo sentido, mas sim de que as estruturas gerais descritas na noção de mundo como unidade (sínteses na consciência, horizonte intencional etc.) também estão presentes, conforme pretendo expor, no conceito de mundo da vida. Essa é a razão pela qual, aliás, acredito ser possível tratar da noção de "mundo", em Husserl, como um termo coerente, mesmo multifacetado, de sua fenomenologia. De acordo com nossa leitura, a chave de interpretação para a noção de mundo - e isso também vale, em particular, para o mundo da vida - é compreendê-la como um conceito amplo e coerente, mas que possui diversas ramificaçóes as quais devem ser analisadas nas suas especificidades.

Seguindo essa linha de interpretação, pretendo demonstrar, através da exposiçấo a seguir, que mundo da vida pode ser compreendido como um conceito coeso e adequado, embora, de fato, seja usado em alguns sentidos mais e outros menos abrangentes. Conforme mencionei, essa é igualmente a tentativa de leitura feita por alguns intérpretes, os quais procuram demonstrar a unidade da noção de mundo da vida, ainda que a partir de elementos com os quais, ao menos em parte, discordo.

Matheson Russell, por exemplo, acredita que, apesar dos diversos usos do conceito, é possível indicar dois sentidos gerais predominantes, que se relacionam entre si: o primeiro, um sentido mais amplo, refere-se ao mundo da vida enquanto o mundo total que é dado na experiência imediata, incluindo aspectos culturais e todas as formas de intersubjetividades. Em uma varian-

7 Não caberia aqui entrar em detalhes sobre a questâo do conceito geral de mundo, na filosofia husserliana. Porém, conforme menciono, entendo tal noçâo como a ideia de que há uma estrutura geral de significação ampla e coerente, dada através de sínteses da consciência, que organiza toda a experiência fenomênica a partir de um horizonte intencional. A novidade da noçáo de mundo da vida, em relação ao conceito geral de mundo, seria sobretudo a ênfase na intersubjetividade. 
te mais restrita, mundo da vida seria empregado como "natureza", enquanto algo invariável culturalmente e que vem a servir de base para a idealização do mundo da experiência natural, tal como realizado pela ciência. Nesse segundo uso, portanto, trata-se de um fenômeno particular do mundo total da experiência e, nesse sentido, de uma "parte abstrata" do mundo da vida total (RUSSELL, 2006, p. 194).

Embora esteja de acordo com o intérprete sobre a possibilidade de identificar dois sentidos gerais para o conceito, discordo de que a ideia de "natureza" como algo universal e "invariável culturalmente" seja um sentido geral significativo e, ainda menos, que seja uma espécie de parte do sentido mais amplo, isto é, abstraída da noção de mundo da vida, enquanto unidade das experiências imediatas. Entendo que esse não é o caso, desde logo, na medida em que a parte "universal" e intersubjetivamente comum do mundo da vida não reside na ideia de natureza ou de "experiência natural", como atestam algumas passagens de Krisis que serão analisadas adiante (HUSSERL, Krisis, \$37-49).

Dan Zahavi, por outro lado, acredita que o sentido da noção de mundo da vida "depende do contexto", e distingue entre um sentido ontológico e outro transcendental. O sentido ontológico, de sua parte, é subdividido em dois: primeiro, mundo da vida diz respeito ao mundo da experiência pré-científica, o qual tomamos como um dado familiar da vida cotidiana; em uma segunda significação, o mundo da vida incluiria as teorias científicas, uma vez que as crenças teóricas da ciência podem ser "assimiladas pela práxis diária", tornando-se, portanto, uma parte do mundo da vida. De acordo com Zahavi (2003, p. 129), “[...] uma das propriedades características desse conceito modificado [segundo sentido ontológico] de mundo da vida é que ele não é estático." O segundo sentido da noção, sua versão transcendental, aponta para o fato de que tanto o mundo da vida, no sentido ontológico, como a ciência são constituídos pela intersubjetividade transcendental, em uma esfera basilar de doação de qualquer mundo e sentido possível. Desse modo, mundo da vida seria, em última instância, a "[...] vida intersubjetiva do mundo da consciência”, mas, agora, transcendentalmente tomada. (ZAHAVI, 2003, p. 132).

Acredito que, em linhas gerais, a interpretação de Zahavi é acertada e que a divisão em um sentido ontológico e outro transcendental é uma boa chave de leitura. Discordo parcialmente, porém, de suas análises: no caso do conceito ontológico de mundo da vida, parece-me que a subdivisáo e consequente "conceito modificado" identificado pelo intérprete não faz sentido algum, porque, em primeiro lugar, o que Zahavi entende como o primeiro 
tipo de mundo da vida ontológico tampouco configura um "mundo estático", no sentido de que em nada se altera; dessa maneira, ser "não estático" não é uma característica distintiva para o suposto segundo conceito ontológico de mundo da vida.

Além disso, o fato de se tratar da "vida pré-científica" não significa de forma alguma que surja contradição com possíveis influências advindas da ciência. É perfeitamente natural, dentro desse sentido amplo de mundo da vida ontológico, que sejamos, em nossa vida cotidiana, influenciados por conhecimentos que a sociedade desenvolveu, a partir da atividade científica - saber, por exemplo, que os planetas giram ao redor do sol. A presença ou ausência de dados de origem científica em nada altera que tal mundo da vida permaneça "pré-científico", pois o que Husserl quer dizer com isso é que se trata de um mundo que náo é vivenciado ao modo como a ciência o entende.

Conforme será detalhado a seguir, o que propriamente separa as duas esferas é, antes de tudo, a concepção científica de mundo, porque a ciência de caráter objetivista ignora seus pressupostos do mundo da vida e trata do mundo como uma realidade idealizada. Isso não significa, por exemplo, que o cientista viva isolado no mundo idealizado da ciência, já que ele também partilha da vida comum concreta. Em verdade, enquanto atividade humana, o fazer científico é parte do próprio mundo da vida; o problema está, justamente, em que a ciência, com seus pressupostos ocultos, não perceba e tampouco explicite tal vinculação.

\section{As MOTIVAÇÓES E ORIGENS DO AFASTAMENTO ENTRE CIÊNCIA E MUNDO DA VIDA}

A partir de uma análise do texto de Krisis, obra na qual a noção de mundo da vida é extensamente desenvolvida, é possível determinar com maior precisão seu sentido e aplicação. $\mathrm{O}$ primeiro aspecto, conforme já mencionado, é a relação direta de tal conceito com aquilo que Husserl chama de "crise das ciências”. Considerando que Krisis surge das conferências realizadas pelo filósofo em Viena e Praga, no ano de 1935, pode parecer surpreendente que, nesse contexto, algo como uma efetiva crise nas ciências fosse identificado.

De fato, Husserl reconhece essa dificuldade, e procura esclarecer o que ele entende como uma crise: não é o caso de negar que a ciência em geral possua rigor metodológico, ou alegar que há qualquer razáo concreta para duvidar sistematicamente de seus resultados. O que ocorre é que a ciência, em razão da 
noção mesma de mundo e cientificidade que guia suas investigaçóes, afastou-se por completo de todas as questôes existenciais caras ao ser humano, e a própria concepção de humanidade se reduz ao escopo de corpos físicos dentre outros corpos físicos, do mesmo modo que mundo é tomado como mero conjunto de "fatos" passíveis de verificação e experimentação, de acordo com os critérios do método vigente para cada campo científico. Nesse modo de proceder, é natural que ocorra um distanciamento e uma perda do sentido da ciência:

Ela [a ciência] exclui de um modo inicial justamente as questóes que, para os seres humanos nos nossos desafortunados tempos, abandonados às mais fatídicas revoluçôes, são as questóes prementes: as questôes acerca do sentido ou ausência de sentido de toda esta existência humana. [...] Que tem a dizer a ciência sobre a razão e a não razão, que tem ela a dizer sobre nós, seres humanos enquanto sujeitos dessa liberdade? A mera ciência dos corpos obviamente nada, pois abstrai de tudo o que é subjetivo. (HUSSERL, Krisis $\$ 2$, p. 4, p. 3, t.a).

Husserl entende que a origem da concepção de ciência que determinou essa cisão com diversos aspectos fundamentais da vivência humana se encontra na "decapitação" que o positivismo científico executou na concepção filosófica desenvolvida a partir do Renascimento. Apesar de poder ser concebida como um "resíduo" do ideal de ciência omni-abrangente que guiava o Renascimento e a Modernidade, o positivismo científico realizou um corte metodológico, excluindo todos os problemas da razão - metafísicos, existenciais, éticos e teológicos - que faziam parte do ideal que inaugurou o pensamento da filosofia moderna. (HUSSERL, Krisis $\$ 3$, p. 5-8, p. 4-6).

Porém, a despeito da exclusão dos problemas da razão, a base da ciência contemporânea encontra suas raízes na ideia diretriz do método da filosofia e ciência da Modernidade, cuja justificativa de seus fundamentos reside na transformação da matemática e na consequente matematização da natureza, efetuada de modo exemplar por Galileu. As tarefas impostas à matemática, nesse contexto, constituem uma novidade estranha ao pensamento da Antiguidade: embora a matemática e a lógica tivessem um lugar de destaque, por exemplo, no pensamento grego antigo, foi somente a partir da filosofia moderna que a realidade passa a ser vista como um "mundo de idealidades", no qual um sistema metodológico particular, fundado em uma concepção específica de matemática, é dado como condição 
para qualquer saber de caráter científico. ${ }^{8}$ (HUSSERL, Krisis $\$ 8$, p. 18-21, p. 15-16).

É já nesse cenário que se inicia o processo que viria a resultar na separação entre ciência e mundo da vida, o que acontece, em primeiro lugar, pela alteração do conceito de mundo e daquilo que é tomado como fonte confiável de experimentação científica. Nas palavras de Husserl, ocorre a substituição do "[...] único mundo alguma vez experienciado e experienciável - o nosso mundo da vida cotidiano - pelo mundo matematicamente substruído das idealidades", substituição essa que "[...] foi rapidamente transmitida aos [...] físicos de todos os séculos subsequentes.” (HUSSERL, Krisis $\$ 9$, p. 49, p. 38). De fato, seria com Galileu que se inaugura a passagem da natureza "pré-cientificamente intuível" para a "natureza idealizada”, todavia, essa tendência segue ganhando espaço e novas consequências para o saber científico.

Desde suas primeiras elaborações, todas as fórmulas e símbolos das ciências passam, cada vez mais, a criar um distanciamento entre a experiência de realidade tal como se dá no mundo da vida cotidiano e no mundo científico matematizado. Isso não significa, reforça Husserl, que a ciência em nada tenha progredido dos tempos de Galileu até a contemporaneidade, ou que todos os seus resultados não passem de ilusões: o filósofo deixa claro que não apenas reconhece como efetivos os avanços científicos, como também entende suas contribuiçôes como fontes genuínas de conhecimento. O problema, no entanto, é que, "[...] apesar de toda a novidade permanece [...] o que é essencial em princípio: a natureza em si matemática, dada em fórmulas, interpretada unicamente a partir das fórmulas." (HUSSERL, Krisis $\$ 9$, p. 53, p. 42).

Essas análises são interessantes, na medida em que a crítica que Husserl desenvolve transcende o contexto científico particular de seu tempo. A atualidade da fase tardia do pensamento husserliano reside, em parte, justamente no

\footnotetext{
${ }^{8}$ A distinção que Husserl traça entre a concepção idealizada de Platáo e Galileu (este último enquanto figura central da matematização da natureza) é explicitada do seguinte modo: "Para o platonismo, o real possuía uma methexis mais ou menos perfeita no ideal. Isto oferecia à geometria antiga possibilidades de uma aplicação primitiva à realidade. Ora, na matematização galilaica da natureza, é esta mesma natureza que é idealizada sob a orientação da nova matemática; ela se torna - em termos modernos também uma multiplicidade matemática”. Husserl esclarece que, embora entenda estar na sua origem, não pretende atribuir a Galileu a mesma concepção científica que critica, na contemporaneidade: “Observamos que Galileu, o filósofo natural e 'pioneiro' da física, não foi ainda um físico no sentido atual; seu pensar não se move ainda, como o do nosso matemático e físico matemático, numa simbologia estranha à intuição, e não lhe podemos imputar aquilo que para nós, em resultado de Galileu e do desenvolvimento histórico que se lhe seguiu, se tornou 'coisas óbvias'." (HUSSERL, Krisis $\$ 9$, p.20-21, 16-17, t.a.).
} 
fato de o filósofo ter reconhecido um padrão que não diz respeito apenas a um modo de fazer ciência, na Europa dos anos 30, mas, antes, a uma concepçáo de cientificidade que permeia a ideia de conhecimento ainda hoje e cujas origens estão nos pressupostos da filosofia ocidental e seu ideal de saber científico.

Husserl indica que parte de tais pressuposiçóes respousa em uma tensão basilar do pensamento filosófico, a qual se relaciona com a separação entre ciência e mundo da vida: a oposiçáo entre o objetivismo e o transcendentalismo, e suas respectivas concepçóes de mundo. No caso do objetivismo, guia-se por uma ideia de mundo na qual existiriam "verdades objetivas" por trás das experiências subjetivas, de maneira que o propósito do conhecimento seria compreender e sistematizar, em uma ciência completa, todas essas verdades universais. $\mathrm{O}$ mundo verdadeiro, portanto, seria náo aquele dado na experiência subjetiva cotidiana, de validade apenas relativa, mas sim o mundo das verdades objetivas e universalmente válidas.

O transcendentalismo, por outro lado, sustenta que o mundo da experiência subjetiva é aquilo que, em primeiro lugar, e adequadamente, podemos chamar de mundo verdadeiro. A elaboração do "mundo da ciência", antes de constituir o que seria propriamente real, nada mais é do que "[...] uma configuração de grau superior, com base no experienciar e pensar pré-científicos, e nas suas realizações de validade respectivas." (HUSSERL, Krisis $\$ 14$, p. 70 , p. 55). Dessa forma, o mais basilar é a própria subjetividade, pois é nela, enquanto "instância última geradora" que se efetua todo e qualquer sentido de ser, incluindo, é claro, a concepção do mundo, tanto no seu sentido primário, enquanto mundo da vida, como em uma significação secundária, enquanto mundo propriamente científico.

Ora, as razóes da separação entre ciência e mundo da vida podem ser explicadas em parte justamente em função dessa tensão na história da filosofia: do lado do transcendentalismo, sobretudo quando procura se desenvolver, apelando para uma "subjetividade psicológica", gera diversas dificuldades e contrassensos, de modo que, para compensar as ameaças de falta de fundamentos seguros, surge a tentação de apelar para modalidades mais ou menos sofisticadas de objetivismo. Este, por sua vez, na tentativa de garantir um mundo universal e objetivo, reforça a separação entre conhecimento e mundo da vida, gerando a ideia de uma realidade "pronta", a qual deve ser desvelada como algo que se encontra por trás das experiências "subjetivas". Com essa concepção, obviamente, o objetivismo ignora a origem mesma de qualquer sentido enquanto instância gerada pela subjetividade. 
Husserl não se pretende, porém, um juiz imparcial dessa oposição filosófica e tampouco nega que sua filosofia tenha uma posição evidente, do lado do transcendentalismo. O que o filósofo reitera, no entanto, é que, do mesmo modo que há diferentes tipos de objetivismo, há ainda diversas formas de realização de uma filosofia transcendental. A fim de evitar os contrassensos do transcendentalismo, incluindo a ideia de uma subjetividade de caráter meramente psicológico e, portanto, subjetivo em um sentido pejorativo, cabe à filosofia desenvolver um pensamento transcendental assentado em bases seguras, guiado por uma ideia de fundamentação rigorosa, tal como ambiciona a fenomenologia ${ }^{9}$ (HUSSERL, Krisis $\$ 14$, p. 70-1, p. 55-56).

\section{Mundo DA VIDA COMO FUNDAMENTO OCULTO E NÁO TEMATIZADO DE TODO CONHECIMENTO}

Perde-se de vista, com a concepção idealizada de natureza e suas consequências para a atividade científica, o papel do mundo da vida na formulação de qualquer conhecimento, mesmo do conhecimento desenvolvido pela ciência. O que Husserl pretende apontar não é que a ciência está necessariamente equivocada em se guiar pelo seu método, porém, que está enganada em não perceber os pressupostos de tal método e as implicaçóes em não reconhecer a base oculta que é condição de qualquer conhecimento, resultando justamente numa separaçáo - agora também existencial - do mundo tomado como científico e da realidade tida como cotidiana e pré-científica.

Ora, mesmo nas certezas mais "banais" do dia a dia e nas crenças mais fundamentais que guiam nossas ações, já há uma induçâo e a busca pela confirmação em alguma evidência. Da mesma maneira, qualquer experimento científico, por mais elaborado que possa ser, tem sua realizaçáo pautada em um contexto próprio que envolve a condição histórica e concreta do investigador e

\footnotetext{
${ }^{9}$ A crítica que Husserl desenvolve a respeito dos fundamentos da ciência nâo é, evidentemente, aceita por todos os seus intérpretes. Majer (2009, p. 47), por exemplo, considera o "anticientificismo" de Husserl "[...] altamente problemático, se não simplesmente equivocado." Ainda que se possa questionar se Husserl de fato nâo faz da ciência um "espantalho" para o desenvolvimento de seus argumentos, náo estou de acordo com Majer de que o filósofo apresente uma postura propriamente anticientificista em Krisis, pois, conforme indiquei, ele reiteradas vezes esclarece que não desconsidera a ciência vigente como fonte de saber e mesmo que a "admira" (Krisis, \$9). Acredito que a crítica que Husserl empreende, usando a ciência como ponto de partida, pretende ser muito mais abrangente e trata, em verdade, das bases da concepção de conhecimento que conduzia a Europa nos anos 30 e, podemos dizer, em grande parte ainda domina o ideal científico de conhecimento, no qual está incluído o desinteresse por tornar evidente os pressupostos, tanto epistemológicos como políticos, os quais guiam o fazer da ciência.
} 
dos conhecimentos tomados atualmente como válidos. Por mais "distanciada" e "imparcial" que a ciência se pretenda, a interpretação de seus resultados, a escolha de seus métodos, a orientação mesma de suas perguntas, enfim, todo o contexto de sua execução acontece enquanto atividade de um ser humano pertencente a um mundo que é partilhado por outros seres humanos e que determina necessariamente seu ponto de vista, seus fins e seus meios.

[...] qualquer estudo retrospectivo ocasional (ou também "filosófico") dirigido ao sentido próprio desse trabalho artificial se detém sempre na natureza idealizada, sem conduzir radicalmente até o fim último que a nova ciência da natureza, com a geometria que dela é inseparável, crescendo a partir da vida pré-científica e do seu mundo circundante, deveria desde o início servir; um fim que, no entanto, reside nesta vida, e a cujo mundo da vida tem de estar referido. Só a este poderia o ser humano que vive neste mundo, entre os quais o pesquisador da natureza, dirigir todas as suas questôes práticas e teóricas, só ao mundo da vida, nos seus horizontes desconhecidos infinitamente abertos se poderia ele referir teoricamente. [...] Toda a prática, com os seus propósitos, implica induçôes, só que os conhecimentos indutivos usuais, e também os expressamente formulados e "conservados" (isto é, as previsóes), são "sem artifício", em contraste com as induçôes artificiais "metódicas", a incrementar até o infinito pelo método da física galilaica na sua capacidade realizadora. (HUSSERL, Krisis $\$ 9$, p. 50-51, p. 39-40, t.a).

Assim, é evidente que a separação entre mundo da vida e saber científico é não somente uma separação artificial - na medida em que, em última instância, sempre realizamos a ciência, com base no solo mesmo deste mundo -, como ingênua: pretende-se, em nome de um ideal de cientificidade, encontrar as verdades que estariam escondidas detrás da experiência de mundo cotidiana, quando, ao contrário, é justamente essa vivência "costumeira" que está na base do mundo idealizado buscado pela saber científico. Sem o "horizonte de entes válidos" da "vida pré-científica" não haveria, em geral, qualquer tipo de conhecimento (HUSSERL, Krisis $\$ 28$, p. 113, p. 89).

Husserl reconhece como um dos aspectos mais significativos do ocultamento do mundo da vida o fato de se perder de vista e se tomar como “óbvios" fenômenos que, uma vez observados de perto, revelam uma enorme importância, ou em desconsiderar por completo uma série de fenômenos que possibilitaram, em primeiro lugar, os conceitos da ciência. Como resultado, o pretenso conhecimento de caráter científico e universal coloca a si mesmo em uma situação paradoxal: de um lado, almeja abranger sob seu método a 
realidade como um todo e encontrar verdades últimas; de outro, desconsidera como digno de nota todo o mundo da vida, a partir da qual o fazer científico tem lugar (HUSSERL, Krisis \$29, p. 114-7, p. 90-92).

Com isso, porém, surge uma dificuldade de grande importância: se o mundo da vida permanece enquanto um fundamento velado de todo conhecimento e se a ciência de caráter positivista é criticada por jamais investigar tais pressupostos, temos o problema de como e com quais meios tornar essa análise viável. Husserl admite que é mais fácil criticar a ciência que não tematiza o mundo da vida do que, de fato, encontrar a maneira de tratar desse tema, uma vez que tal empreendimento teórico implica, em primeiro lugar, questionar que tipo de cientificidade é possível, de acordo com o tópico em questão - mantendo-se fiel, portanto, à máxima fenomenológica por nós conhecida, segundo a qual o modo mesmo de ser de cada fenômeno determina o tipo de conhecimento possível de ser desenvolvido.

Não é tarefa fácil alcançar com clareza acerca de que tipo de tarefas especificamente científicas, ou seja, universais, se devem definir sob o nome mundo da vida, e em que medida deve daqui resultar algo de filosoficamente significativo. Levanta dificuldades já o mais elementar entendimento do seu sentido de ser específico, sentido que ora deve ser apreendido de modo mais lato, ora mais estreito (HUSSERL, Krisis \$33, p. 124, p. 99).

A dificuldade de determinar o modo e meios de investigação é, portanto, especialmente complexa nesse caso, porque, conforme Husserl reconhece, nem mesmo um sentido de todo fixo é encontrado para a noção de mundo da vida: sua maneira mesma de ser implica que haja um sentido mais ou menos amplo para compreendê-la, acrescentando à determinaçáo do caminho de análise o obstáculo da própria equivocidade de seu objeto de estudo. Conforme pretendo mostrar, porém, o filósofo procura resolver essa dificuldade, através do método próprio da fenomenologia e, com isso, encontrar no mundo da vida aquilo que seriam suas estruturas fundamentais e universais.

\section{O CAMINHO E O MÉTODO PARA UMA ANÁLISE FILOSÓFICA DO MUNDO DA VIDA: A ABERTURA À INTERSUBJETIVIDADE}

A apreensão e análise filosófica do mundo da vida se apresenta como um problema a ser destrinchado, tanto no seu ponto de partida como nos seus resultados. Visto que a ciência de caráter positivista se mostrou incapaz de tema- 
tizar esse fenômeno, caberá à fenomenologia questionar, em primeiro lugar, que tipo de noção de cientificidade é cabível, nesse contexto. Há de se distinguir, portanto, a ideia de ciência enquanto atividade científica concretamente realizada - a qual, como vimos, se baseia sobretudo no que Husserl entende por um objetivismo -, e ciência enquanto campo mais amplo de conhecimento.

Como questiona o filósofo, "[...] talvez a cientificidade que este mundo da vida [...] exige, seja uma cientificidade específica, justamente não lógico-objetiva, e que como a cientificidade fundamentadora última, o seu valor não seja o de cientificidade menor, mas superior." (HUSSERL, Krisis $\$ 34$, p. 127, p. 101). O argumento elaborado por Husserl recorre, conforme já indiquei, à ideia de que o mundo da vida é justamente a base a partir da qual qualquer experiência é constituída. Nesse sentido, a concepção de experimentação guiada pelo método científico vigente e o conceito de mundo objetivo da ciência são secundários e derivados quanto ao mundo da vida originário. Em um sentido amplo, o mundo da vida abrange o mundo da ciência objetivista, mas o contrário não é verdadeiro.

A ideia mesma de "experiência" é um exemplo adequado do equívoco por trás da concepção científica de mundo objetivo: a experiência imediata não é aquela realizada pela ciência vigente, porque esta faz constantemente uso de mediaçóes, tais como instrumentos e símbolos, de sorte que a evidência mais imediata concebível é a que forma o conjunto coerente de horizontes do mundo da vida. A “concepção das retas geométricas” não é, certamente, uma evidência primária em relação às "arestas retas da mesa”, e considerar a anterioridade da geometria em relaçáo às experiências que, ao menos em parte, possibilitaram sua formulação, seria inverter a ordem efetiva da doação de evidências (HUSSERL, Krisis \$34, p. 132, p. 105).

Diante de tudo isso, poderíamos, no entanto, questionar: uma vez que, conforme Husserl reconhece, o método científico vigente, a despeito de seus pressupostos não explicitados, alcança resultados desejáveis dentro de seus propósitos e que a vida prática cotidiana decorre perfeitamente bem com seus modos próprios de evidências, sem necessitar, para tanto, de nenhuma tematização filosófica particular, em que medida faz sentido buscar uma análise científica para o mundo da vida, mesmo na busca de uma nova noção de cientificidade? Husserl antevê esse tipo de objeção e questiona se, de fato, “[...] uma temática específica intitulada 'mundo da vida' seria um exercício intelectualista, derivado de uma ambição própria da vida moderna, a ambição de tudo teorizar." (HUSSERL, Krisis \$34, p. 135, p. 108). 
O filósofo se defende, alegando que se conformar com tal situação é nada fazer diante da crise das ciências, as quais, como vimos, parecem nada mais ter a dizer ao ser humano concreto e suas questôes mais caras, assim como aceitar a condição da filosofia como uma atividade de menor valor, que não alcança jamais o estatuto de ciência. Além disso, não trazer essas questóes ao debate implica aceitar a manutenção da ingenuidade em que se move o fazer científico. Dada justamente a orientação pragmática da ciência, e seu aparente sucesso no alcance de resultados e dados tomados por puros e simples "fatos", não há, ao fim e ao cabo, nenhuma outra disciplina capaz de questionar os fundamentos ocultos do que se entende por conhecimento, a não ser a própria filosofia.

O caminho para tal análise será, em primeiro lugar, perceber quais são os elementos fundamentais do mundo da vida, como o fato de abranger "o intuir e o intuído antes da teoria" e de ser "o mundo das experiências simplesmente intersubjetivas.” (HUSSERL, Krisis \$34, p. 136-8, p. 109). As consideraçôes de Husserl seguem na direção já conhecida do meio de acesso para o campo fenomenológico transcendental: os métodos de redução, ainda que, nesse contexto, a partir da passagem progressiva da epoché para a redução.

É importante mencionar, ainda, que, embora nem sempre seja observada pelos intérpretes, há uma distinção entre epoché e redução: a primeira seria um momento da segunda, pois diz respeito ao primeiro passo da redução, que é a suspensão de juízo sobre a existência dos objetos do mundo. O segundo passo, o qual é o que podemos entender por redução fenomenológica propriamente, refere-se a, partindo de tal suspensão de juízo, passar da atenção dos objetos de nossa experiência para o modo como eles são experienciados.

Porém, já nesse primeiro passo, deparamos, é claro, com uma dificuldade de princípio na aplicação do método de redução para um objeto tal como o mundo da vida: ora, como o mundo da vida é compreendido enquanto a vida cotidiana pré-científica, essencialmente intersubjetiva, é questionável se algo poderia se manter, uma vez efetuada a redução. $\mathrm{O}$ mundo da vida varia em grande medida, enquanto mundo concreto e compartilhado, de acordo com cada cultura e contexto, parecendo, à primeira vista, tratar-se de uma realidade essencialmente múltipla e mesmo relativa. Se, pela redução, há a abstenção da tese sobre a existência do mundo e o fechamento, por assim dizer, no solipsismo transcendental, o que poderia restar do mundo da vida? Isso não iria contra sua natureza intersubjetiva? 
A resposta de Husserl vai na direção da defesa de um a priori próprio do mundo da vida, o qual consiste na "estrutura geral" que se revela a partir da redução e que aponta para algo de universal, a despeito da pluralidade de experiências possíveis. Os elementos mais basilares de tal estrutura dizem respeito à diferença no modo como se dá a experiência de consciência do mundo, de um lado, e dos objetos do mundo, de outro. Os objetos são experienciados não como meros entes isolados, mas sim enquanto coisas em uma realidade coerente, e pressupóem, portanto, um "horizonte de mundo". O próprio mundo, por sua vez, não é jamais tomado como mero objeto, porém, como uma "unicidade singular" que justamente serve de horizonte de estruturação para todos os entes (HUSSERL, Krisis \$37, p. 145-146, p. 106-107).

Seguindo o procedimento aberto pela redução, cabe ao filósofo investigar o mundo da vida, não enquanto conjunto de experiências concretas, contudo, agora enquanto fenômeno dado à consciência e buscar, nesse processo, explicitar todas as estruturas que se mostrarem universais na experiência de mundo. Nessa análise, cabe examinar o mundo, em primeiro lugar, "como ele é subjetivamente dado" pela consciência transcendental e, nesse sentido, parte-se certamente de um solipsismo. Tal investigação, no entanto, desenvolve-se de maneira progressivamente complexa, revelando inicialmente a maneira como ocorre a "formação de sentido" de mundo na consciência transcendentalmente isolada (HUSSERL, Krisis $\$ 44,45,46$ ), mas demonstrando, em seguida, como a própria consciência do ego puro encontra em si o caminho para a universalidade e a intersubjetividade.

Neste aprofundamento exclusivo das multiplicidades dos modos subjetivos de aparição em que o mundo é dado, ilumina-se para nós [...] a intelecção de que não se trata aqui de factualidades contingentes, mas, muito pelo contrário, de que nenhum ser humano imaginável, e por mais transformado que pensemos, poderia experienciar um mundo noutras maneiras de doação, a não ser na relatividade incessantemente mutável por nós em geral circunscrita, como um mundo previamente dado na vida da consciência e em comunidade com uma co-humanidade. [...] O ente, em qualquer sentido concreto ou abstrato, real ou ideal, tem as suas maneiras de autodoação e, da parte do eu, as suas maneiras de intenção em modos de validade, onde se incluem as suas maneiras de transformaçôes subjetivas dessas validades nas suas sínteses de concordância e discordância, individual-subjetivas e intersubjetivas. (HUSSERL, Krisis $\$ 48$, p. 168169, p. 134-135, t.a.). 
Assim, a noção de mundo da vida se mostra perfeitamente compatível com o método de redução, ficando demonstrado ser possível tratar filosoficamente desse tema, dentro do escopo da fenomenologia transcendental, a partir da descrição de suas estruturas fundamentais, incluindo as "sínteses de concordância", tanto subjetivas como intersubjetivas. A maneira concreta como o desenvolvimento de tal análise se dá, no entanto, depende da compreensão adequada da justificativa para a intersubjetividade transcendental, pois, conforme foi indicado, a abertura para o campo intersubjetivo é uma das características essenciais do mundo da vida concretamente experienciado.

Outro ponto importante que se esclarece, com esta exposição, é a solução da aparente ambiguidade do conceito: conforme explicitei anteriormente, estou de acordo com os intérpretes de que há equivocidade na noção de mundo da vida, todavia, não de que não haja, a despeito disso, uma unidade coerente. A unidade se dá justamente na medida em que o conceito transcendental de mundo da vida se relaciona à descrição de suas estruturas universais e gerais, de seu a priori. Nesse sentido, há, é claro, abstração de certos aspectos do fenômeno. Mundo da vida, no sentido ontológico, porém, enquanto experiências da vida concreta pré-científica e cotidiana, envolve a descrição do fenômeno do ponto de vista filosófico, mas não, ainda, transcendental.

Uma questão, no entanto, que pode ser apontada como uma dificuldade é até que ponto podemos de fato encontrar qualquer aspecto de propriamente "efetivo" e referente à "vida concreta", nessa versão mais geral do conceito de mundo da vida. Em outras palavras, a dificuldade que aparece aqui é que, com tal noção, Husserl pretendia justamente criticar o intelectualismo e o distanciamento da ciência em relação à vida enquanto experiência concreta, a qual envolve as vivências pré-científicas e cotidianas; porém, ao observarmos o modo como ele desenvolve sua análise, para apreender essa esfera, vemos que, paradoxalmente, o filósofo é levado a um método inicialmente solipsista e que pretende tratar de toda a realidade enquanto fenômeno, com base em uma consciência pura reduzida.

Ou seja, em que medida podemos, de fato, afirmar que esse procedimento representa um avanço significativo quanto ao ponto de vista exclusivamente teórico que guia a ciência, se, também na fenomenologia, a investigação é conduzida a partir de um método que coloca a consciência pura como esfera prioritária e que pretende estabelecer, em primeiro lugar, todos os aspectos supostamente universais e absolutos da experiência de mundo? Faria sentido, 
na verdade, conceber uma análise presa à ideia de fundamentação última e $a$ priori como sendo coerente com a concepçáo de mundo da vida enquanto realidade que transcende a teoria? Como apontei, porém, uma vez que a noção de mundo da vida está conectada necessariamente com a intersubjetividade, caberia analisar, primeiramente, a maneira como Husserl procura justificar, no interior mesmo da redução, o estabelecimento de um mundo comum e partilhado, o que pretendo desenvolver em outra ocasião.

MISSAGGIA, J. The Husserlian notion of lifeworld (Lebenswelt): a case for its unity and coherence. Trans/form/ação, Marília, v. 41, n. 1, p. 191-208, Jan./Mar., 2018.

\begin{abstract}
This paper discusses some of the controversial issues concerning the concept of lifeworld (Lebenswelt) as it is laid out by Edmund Husserl. Despite its multiple usages, I argue that this notion must be construed as univocal, and as endowed with internal coherence throughout Husserl's work. So as to present this argument more fully, I examine the connection between lifeworld and science, as well as the former's contribution to knowledge and its relation to intersubjectivity, all of these themes being key concerns in the context of Husserl's later thought.
\end{abstract}

KeYwords: Edmund Husserl, Lifeworld, Science, Knowledge, Intersubjectivity.

\title{
REFERÊNCIAS
}

CARR, D. Phenomenology and the problem of history: a study of Husserl's transcendental philosophy. Evaniston, Illinois: Northwestern University Press, 1974.

. Husserl's problematic concept of the life-world. In: ELLISTON, F.;

MCCORMICK, P. (Ed.). Husserl: expositions and appraisals. Notre Dame, IN; London: University of Notre Dame Press, 1977. p. 202-212.

DODD, J. Crisis and reflection: an essay on Edmund Husserl's Crisis of the European sciences. Dordrecht: Kluwer, 2005. (Phaenomenologica, v. 174).

DRUMMOND, J. J. Historical dictionary of Husserl's philosophy. Lanham: Scarecrow, 2008.

HABERMAS, J. Theorie des kommunikativen Handelns I-II. Frankfurt am Main: Suhrkamp, 1981.

HELD, K. Husserl's phenomenology of the life-world. In: WELTON, D. (Ed.). The New Husserl: a critical reader. Bloomington: Indiana University Press, 2003. p. 32-62. 
HUSSERL, E. Husserliana 4. Ideen zu einer reinen Phänomenologie und phänomenologischen Philosophie. Zweites Buch: Phänomenologische Untersuchungen zur Konstitution. Ed. Marly Biemel. The Hague: Martinus Nijhoff, 1952.

. Husserliana 9. Phänomenologische Psychologie. Vorlesungen Sommersemester 1925. Ed. Walter Biemel. The Hague: Martinus Nijhoff, 1962.

. Husserliana 1. Cartesianische Meditationen und Pariser Vorträge. Ed. Stephan Strasser. Den Haag: Martinus Nijhoff, 1950, rpt. 1973. . Meditaçôes cartesianas e conferências de Paris. Rio de Janeiro: Forense Universitária, 2012.

. Husserliana 6. Die Krisis der europäischen Wissenschaften und die transzendentale Phänomenologie. Eine Einleitung in die phänomenologische Philosophie. Ed. Walter Biemel. The Hague: Martinus Nijhoff, 1954, rpt. 1962. . A crise das ciências europeias e a fenomenologia transcendental. São Paulo: Forense Universitária, 2012. MAJER, U. The origin and significance of Husserl's notion of the lebenswelt. In: HYDER, D.; RHEINBERGER, H-J. (Ed.). Science and the life-world: essays on Husserl's Crisis of European sciences. California: Stanford University Press, 2009.

RUSSELL, M. Husserl: a guide for the perplexed. London: Continuum, 2006.

SCHÜTZ, A.; LUCKMANN, T. Strukturen der Lebenswelt. Frankfurt am Main: Suhrkamp, 1979.

ZAHAVI, D. Husserl's Phenomenology. California: Standford University Press, 2003.

Recebido: 26/12/2015

Aceito: 15/10/2016 